Original article

Paediatrics Today 2015;11(2):154-159

DOI $10.5457 / \mathrm{p} 2005-114.121$

\title{
UNRECOGNIZED ELEVATED BLOOD PRESSURE IN THE 3-18 YEAR OLD POPULATION IN THE PRIMARY CARE SETTING
}

\author{
Steven KAIRYS*, Samuel WERZBERGER
}

Jersey Shore University Medical

Center Neptune, New Jersey, USA

*Corresponding author:
SKairys@meridianhealth.com
Tel.: + 0116095774582
Fax.: + 0117327762344

Received: July 7, 2015

Accepted: August 27, 2015

Key words: Children - Adolescents • Hypertension • Elevated blood pressure • Primary care.

\begin{abstract}
Objective - This study was done to assess the incidence of missed elevated blood pressure readings at two large outpatient clinics. Methods - We randomly selected 250 charts from all pediatric well child visits seen at the two sites during 2014. Recognized elevated blood pressure was the primary outcome. We reviewed the charts to determine if systolic and/or diastolic blood pressure was greater than the $90^{\text {th }}$ percentile for age, gender and height or greater than $120 / 80 \mathrm{mmHg}$ in patients without a previous history of elevated blood pressure. The charts were then reviewed to see if the practitioners in any way recognized the elevated blood pressure reading, either by repeating the reading, a clinic note documenting the high reading, a plan to recheck in the future, relevant lab work, imaging, or a referral to a pediatric cardiologist or nephrologist. Results - There were 72 (28.8\%) children with elevated blood pressure readings. Twenty nine $(40.3 \%)$ of these children were recognized as having elevated readings based on the criteria listed above. Twelve of these 29 children had other interventions taken. Forty three of these 72 children $(59.7 \%)$ were not recognized and no intervention was taken. Conclusion - Almost $60 \%$ of children with elevated blood pressure readings taken as part of the well child visit were not recognized in provider documentation. Practitioners should be aware of this common pediatric diagnostic error. Appropriate measures such as training, use of a blood pressure simplified charts, or electronic alerts should be taken to reduce the amount of missed diagnoses.
\end{abstract}

\section{Introduction}

Hypertension is an increasing high problem in pediatrics with the incidence increasing over the past 20 years from approximately $1 \%$ of children to as high as $4.5 \%$ (1). And recent data from the American Heart Association estimates that as many as $15 \%$ of adolescents have elevated blood pressure readings (2). A number of children already have left ventricular hypertrophy at the time of diagnosis (3). Some of the increase could be ex- plained by the obesity epidemic. Because of the significance of hypertension causing long term morbidity and increased mortality, the American Academy of Pediatrics recommends blood pressure checks at every well child visit from age 3 years onward. Despite this guideline, pediatricians have been shown to underdiagnose hypertension in children (4).

The definition of hypertension in children and adolescents is based on the normative distribution of BP in healthy children. 
Hypertension is defined as average systolic blood pressure (SBP) and/or diastolic blood pressure (DBP) that is greater than or equal to the $95^{\text {th }}$ percentile for sex, age, and height on three or more occasions. Pre-hypertension is defined as average SPB and/or DBP levels that are greater or equal to the $90^{\text {th }}$ percentile but less than the $95^{\text {th }}$ percentile As with adults, adolescents with blood pressure readings greater or equal to $120 / 80 \mathrm{mmHg}$ should be considered elevated. The preferred method for blood pressure measurement is auscultation with a cuff that is appropriate for the child's upper arm. Thus for an infant this usually means a cuff that is $6 \mathrm{~cm}$ wide and $12 \mathrm{~cm}$ in length. For a child the usual size is $9 \mathrm{~cm}$ wide and $18 \mathrm{~cm}$ in length. For an adolescent with a maximum arm circumference of $26 \mathrm{~cm}$ the cuff would need be $10 \mathrm{~cm}$ wide and $24 \mathrm{~cm}$ in length (2).

This under-diagnosis, missed diagnosis, is one form of diagnostic error, the other forms being delays in diagnosis and wrong diagnosis (5). These errors appear to be very common in the outpatient setting. A recent survey of pediatricians in the United States of America (USA) reported that 54\% make a diagnostic error at least once or twice a month; that $45 \%$ make an error that harms a patient at least once or twice a year and that even these high percentages are under-estimated (6).

Hypertension in children is almost always asymptomatic. When the elevated blood pressure readings are repeated and consistently high, the usual cause in adolescents is familial or secondary to obesity. In younger children, the etiology is often organic, caused by renal disease $(68 \%)$, endocrine $(1 \%)$, renovascular $(10 \%)$, and then cardiac, neurologic or pharmacologic (7).

There have been very few studies researching outpatient pediatric patient error, whether due to delays, wrong diagnosis, or missed diagnosis $(8,9)$. We developed a project to research the incidence of missed diagnoses of elevated blood pressure readings in two large outpatient clinics in Central New Jersey (NJ).

\section{Subjects and methods}

We randomly selected 250 pediatric charts from two outpatient practices, staffed by 12 pediatricians, who were seen during 2014 for well child care. The practices are the Family Health Center in Neptune NJ and a federally qualified public health center in Lakewood, NJ. These practices care for children who are approximately 50\% Latino, 30\% Caucasian, and 20\% African-American. Each site cares for over 3000 children each year. Charts were assigned based on age ranges so that there was representation from preschool, school aged and adolescent populations. All patients had been seen for well child care within the previous six months. Auscultation of blood pressure was the method used in both practices. We did not have details of the actual blood pressure device.

Each chart was reviewed to see if the SBP and/or DBP recorded was above the $90^{\text {th }}$ percentile based on the child's age, gender, and height, or greater than $120 / 80 \mathrm{mmHg}$ for any patient. Age of the patient and the actual elevation of blood pressure were recorded.

The charts were then reviewed to see if the elevated blood pressure was recognized by the pediatrician. Evidence of recognition included evidence that the blood pressure measurement was repeated at that visit, that the clinic note mentions the elevated blood pressure, that a plan was written that calls for a re-check, that relevant lab work or imaging was ordered, or that a referral was made to cardiology or nephrology.

\section{Ethics statement}

The research was approved by the Jersey Shore University Medical Center IRB. All procedures are in accordance with the Declaration of Helsinki. IRB approval was received prior 
to the chart review. Since the charts were assessed for only de-identified demographic and blood pressure data, informed consent was not required by the IRB.

\section{Statistical analysis}

Data was analyzed using Excel Spread Sheets and presented as numbers and percentages of cases.

\section{Results}

The children ranged in age from 3 to 18 years of age, with similar numbers of children from each age range (Table 1$)$.

\begin{tabular}{lll}
$\begin{array}{l}\text { Table } 1 \text { Age distribution of primary care charts } \\
\text { reviewed for blood pressure }\end{array}$ \\
\hline $\begin{array}{lll}\text { Age } \\
\text { (years) }\end{array}$ & $\begin{array}{l}\text { Numbers of } \\
\text { charts }(250 \text { total })\end{array}$ & $\begin{array}{l}\text { Number } \\
\text { of males }\end{array}$ \\
\hline 3 & 5 & 3 \\
4 & 9 & 4 \\
5 & 12 & 7 \\
6 & 20 & 12 \\
7 & 20 & 9 \\
8 & 22 & 14 \\
9 & 24 & 11 \\
10 & 30 & 17 \\
11 & 12 & 7 \\
12 & 14 & 6 \\
13 & 12 & 6 \\
14 & 14 & 8 \\
15 & 12 & 5 \\
16 & 44 & 28 \\
\hline
\end{tabular}

There were $72 / 250$ children (28.8\%) with blood pressure readings greater than the $90^{\text {th }}$ percentile for SBP and/or DBP. Of these 72 children, 29 of them $(40.3 \%)$ were recognized by the pediatrician as having elevated blood pressure and had their blood pressure repeated. Of these 29 recognized elevated blood pressure recordings, 12 had high readings on more than one occasion and other interven- tions were instituted (lab work, imaging, or referral to a cardiologist or nephrologist). The age distribution for the elevated blood readings was similar to the distribution for the age range on the chart review (Table 2).

\begin{tabular}{lll}
$\begin{array}{l}\text { Table } 2 \text { Age distribution of missed elevated } \\
\text { blood pressure readings }\end{array}$ \\
\hline $\begin{array}{l}\text { Age } \\
\text { (years) }\end{array}$ & $\begin{array}{l}\text { Number } \\
\text { missed (43) }\end{array}$ & $\begin{array}{l}\text { Number } \\
\text { of males }\end{array}$ \\
\hline 3 & 3 & 3 \\
4 & 3 & 2 \\
5 & 2 & 1 \\
6 & 3 & 2 \\
7 & 3 & 2 \\
8 & 4 & 3 \\
9 & 4 & 2 \\
10 & 5 & 2 \\
11 & 2 & 1 \\
12 & 2 & 0 \\
13 & 2 & 2 \\
14 & 3 & 2 \\
15 & 2 & 3 \\
16 & 5 & \\
\hline
\end{tabular}

Forty three of children $(59.7 \%)$ with elevated readings were not recognized and no intervention was taken. Of these, 9 children (20\%) had readings that were about the $95^{\text {th }}$ percentile for age, gender and height.

\section{Discussion}

Diagnostic error in outpatient pediatric practice is only recently beginning to be investigated. Graber et al. looking at internal medicine found that inadequate knowledge was an uncommon reason for error (10). More common was failure to consider the diagnosis because of faulty synthesis or misjudging the salience of the findings. Singh used analysis of electronic records in primary care internal medicine and found significant diagnostic errors often due to erroneous clinician interpretation of the results (11). Shojania et al. 
found a $24 \%$ rate of diagnostic error based on autopsy detected error (12).

For pediatric elevated blood pressure, Brady et al. found $39 \%$ of children in their study of primary care pediatricians had elevated blood pressure readings and that these high readings were missed $87 \%$ of the time 13). This missed diagnosis occurred despite clear guidelines for pediatric hypertension diagnosis (14).

Croskerry et al. believes that a major reason for error is cognitive error, failures of perception, now termed Cognitive Dispositions to Respond (CDRs) (15). The CDR's that would apply to missed diagnoses include overconfidence (acting on incomplete information) and omission bias (failure to consider the diagnosis). This may be more important than system issues. Most error involves both cognitive and system causes and improvements need to address both (15).

Failure to recognize elevated blood pressure is most often due to a failure to understand the normal values for blood pressure tracking that occurs as a child ages. This tracking is also based on gender and height. Charts do exist to document these varying values, but most pediatricians do not remember the value changes, or do not have a system to be alerted to an age specific elevated blood pressure reading (Fig.1).

Thus a SBP of $105 \mathrm{mmHg}$ is over the $90^{\text {th }}$ percentile for a 4 year old, and a DBP of $63 \mathrm{mmHg}$ is over the $90^{\text {th }}$ percentile for that same 4 year old. For a 10 year old a SBP over $115 \mathrm{mmHg}$ is over the $90^{\text {th }}$ percentile

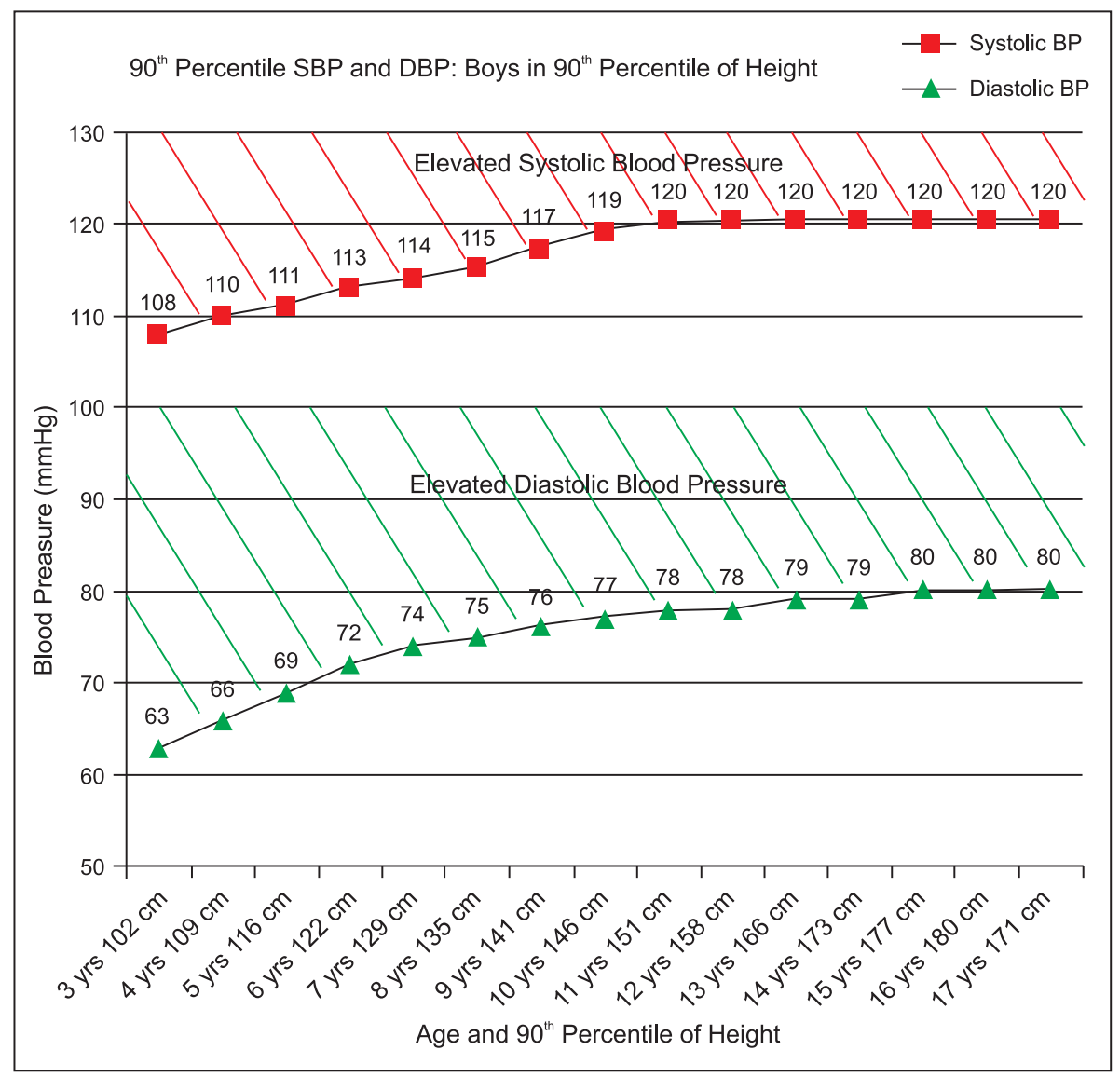

Fig. 1 Simplified chart for tracking blood pressure in children (boys)-chart attributed to Dr Tammy Brady MD, John Hopkins, presented with permission (18, 2). 
and a DBP of $76 \mathrm{mmHg}$ is over the $90^{\text {th }}$ percentile for that same 10 year old. Many pediatricians seem to be aware that $120 / 80$ $\mathrm{mmHg}$ is high in a pre-pubertal child but using this as the standard will miss a majority of elevated blood pressure readings (15). Brady developed an alert system for an electronic medical record system to notify pediatricians when an intake blood pressure was elevated. The alert was a hard stop and could only be overturned by selecting: a) provider needs to obtain manual blood pressure, or b) manual repeat completed. This did increase recognition of elevated blood pressure readings from $12.5 \%$ to $42 \%$, a significant improvement. It was surprising that over $55 \%$ of encounters were still missed (16).

There are a number of potential methods to decrease the missed blood pressure readings. One is to have available an easy to follow 'cheat sheet' that could be placed in every examination room for easy analysis by age and gender at least for the blood pressure $90^{\text {th }}$ percentile (Fig. 1).

This would fit with several of Croskerry's et al. strategies, decrease reliance on memory and making the task easier (15). Periodic chart reviews and feedback are also effective ways to make the issue more visible to doctors, as is general training about hypertension in order to develop more insight and awareness of the problem. Redundancy in the office, a system solution whereby the pediatrician is augmented by the nurse who may have taken the blood pressure also having some responsibility to review the blood pressure and make a notation based on the guidelines, can also be very useful (17).

The recommendations for screening for blood pressure include: 1) children greater than 3 years of age should have a blood pressure taken, 2) the preferred method of blood pressure measurement is auscultation, 3) correct measurement requires a cuff that is appropriate to the size of child's upper arm,
4) elevated blood pressure readings must be confirmed on repeated visits before characterizing the child as having hypertension and 5) measurements that exceed the $90^{\text {th }}$ percentile obtained by oscillometric devices should be repeated by auscultation. Cuff size is calculated so that the largest arm diameter would still allow the bladder of the blood pressure cuff to encircle the arm by at least $80 \%$.

As always the first step is to be aware that missed blood pressure readings are a significant source of ambulatory diagnostic error and that the consequences of missed blood pressure can lead to major morbidity for that individual. As stated there are a variety of potential solutions all dependent on someone in the practice making the concern a priority and using a quality improvement mindset to offer changes, measure impact and re-work based on the checked measures.

There are many aspects of ambulatory care that are subject to diagnostic errors. This research focused only on missed elevated blood pressure readings. Many encounters with children miss important diseases. Often the clinic does not use evidence based screening tools and thus fails to detect such prevalent problems as autism, depression, developmental delays. These are also missed diagnoses. Many clinics are organized to care for episodic illness and are not medical homes that have systems in place to track their children with chronic illness. Thus they do not know who is regularly coming in for care and who is potentially not following protocol. Too often laboratory reports or radiologic results or consultant notes are missing from the chart at the time of the visit and thus misdiagnosis is possible. Electronic records provide some assistance to these issues but there needs to be much more research and understanding about the range of diagnostic error in outpatient care and its short and long term impact on child health. Medical error is not only in the province of hospital based medicine. 
Authors' contributions: Conception and design: SW; Acquisition, analysis and interpretation of data: SW; Drafting the article SK; Revising it critically for important intellectual content: SK.

Conflict of interest: The authors declare that they have no conflict of interest.

\section{References}

1. Muntner P, He J, Wildman RP, Whelton PK. Trends in blood pressure among children and adolescents. JAMA. 2004;291:2107-13.

2. National High Blood Pressure Education Program Working Group on High Blood Pressure in Children and Adolescents (2004). The fourth report on diagnosis, evaluation, and treatment of high blood pressure in children and adolescents. Pediatrics. 2004;114:555-76.

3. Lloyd-Jones D, Adams RJ, Brown TM, Carnethon M, Dai S, De Simone G, et al. Subcommittee. Executive summary: heart disease and stroke statistics - 2010 update: a report from the American Heart Association. Circulation. 2010;121(7):948-54.

4. Graber ML, Franklin N, Gordon R. Diagnostic error in internal medicine. Arch Int Med. 2005;165:1493-9.

5. Graber ML. The incidence of diagnostic error in medicine. BMJ quality and safety. 2013;23:489-94.

6. Singh H, Thomas EJ, Wilson L, Kelly PA, Pietz K, Elkeeb D, et al. Errors of diagnosis in pediatric practice: a multisite survey. Pediatrics. 2010;126(1):70-9.

7. Lurbi E, Alvarez J, Redon J. Diagnosis and Treatment of Hypertension in children. Curr Hypertens Rep. 2010;12:480-6.

8. Bjlsma MW, Blufpond HN, Kaspers GJ, Bokenkamp A. Why pediatricians fail to diagnose hypertension: a multisite study. J Pediatr. 2014;164:1737.e7.
9. Kostopoulou O, Delaney BC, Munro CW. Diagnostic difficulty and error in primary care- a systematic review. Family Practice. 2008; 25:410-13.

10. Graber ML, Franklin N, Gordon R. Diagnostic error in internal medicine. Arch Int Med. 2005;165:1493-9.

11. Singh H, Giardina MA, Meyer AD, Forjuoh SN, Reis MD, Thomas EJ. Types and origins of diagnostic errors in primary care settings. JAMA Int Med. 2013;173(6):418-25.

12. Shojania KG, Burton EC, MdDonald KM, Goldman L. Changes in rates of autopsy-detected diagnostic errors over time: a systematic review. JAMA. 2003;158:381-9.

13. Brady TM, Solomon BS, Neu AM, Siberry GK, Parekh RS. Patient, provider, and clinic-level predictors of unrecognized elevated blood pressure in children. Pediatrics. 2010;125:e1286-93.

14. Falkner B, Daniels SR. Summary of the fourth report in the diagnosis, evaluation and treatment of high blood pressure in children and adolescents. Hypertension. 2004;44:387-8.

15. Croskerry P. The Importance of cognitive errors in diagnosis and strategies to minimize them. Acad Med. 2003;78:775-80.

16. Brady TM, Neu AM, Miller ER 3rd, Appel LJ, Siberry GK, Solomon BS. Real-time electronic medical record alerts increase high blood pressure recognition in children. Clin Pediatr (Phila). 2015;54(7):667-75.

17. Singh H, Graber ML, Kissam SM, Sorensen AV, Lenfestey NF, Tant EM, et al. System-related interventions to reduce diagnostic errors: a narrative review. BMJ Qual Saf. 2012;21(2):160-70.

18. Brady TM, Solomon BS, Neu AM, Siberry GK, Parekh RS. Patient, provider and clinic-level predictors of unrecognized elevated blood pressure in children. Pediatrics. 2010;125:e1286-93. 